\title{
Study on the Professional Identity of Japanese Traditional Craftspeople: Through Interviews with Maki-e Craftspeople
}

\author{
Chieko Narita1, Yutaro Shimode ${ }^{2}$, Kazushi Yamada ${ }^{*}$, Noriyuki Kida ${ }^{3}$ \\ ${ }^{1}$ Department of Advanced Fibro-Science, Kyoto Institute of Technology, Kyoto, Japan \\ ${ }^{2}$ Faculty of Cultural Studies, Kyoto Sangyo University, Kyoto, Japan \\ ${ }^{3}$ Department of Applied Biology, Kyoto Institute of Technology, Kyoto, Japan \\ Email: *kazushi@kit.ac.jp
}

Received 16 October 2015; accepted 8 November 2015; published 11 November 2015

Copyright (C) 2015 by authors and Scientific Research Publishing Inc.

This work is licensed under the Creative Commons Attribution International License (CC BY). http://creativecommons.org/licenses/by/4.0/

c) (i) Open Access

\section{Abstract}

This study focused on the formation process of the professional identity of Maki-e craftspeople, which is one of the Japanese traditional crafts. This study aimed to clarify the professional identity of Maki-e craftspeople by comparing skilled craftspeople and young craftspeople. The participants were four Maki-e craftspeople held in different positions, and semi-structured interviews about the professional identity were conducted. As a result, the three unchangeable aspects of the professional identity of Maki-e craftspeople were shown through this research. Furthermore, the two professional identities of Maki-e craftspeople over the course of the social changes were shown. The knowledge gained from this study is important to achieve greater understanding of career formation in highly specialized occupation.

\section{Keywords}

Component, Professional Identity, Traditional Craftspeople, Maki-e

\section{Introduction}

\subsection{Diversification of Work Styles and Expertise}

What do people ask for from their work? Various reasons and purposes for work are expected, such as worth, satisfaction, and self-expression. Additionally, how do people choose their occupations, and how do they be-

"Corresponding author.

How to cite this paper: Narita, C., Shimode, Y., Yamada, K., \& Kida, N. (2015). Study on the Professional Identity of Japanese Traditional Craftspeople: Through Interviews with Maki-e Craftspeople. Advances in Anthropology, 5, 282-293. 
come experts? Several studies concerning expertise and experts have been conducted (Shanteau et al., 2002; Van Gog et al., 2005; Baker et al., 2006); however, very few have focused on expertise from the point of view of career decision and work. The process of making a career decision and gaining expertise is part of working, and working is closely related to the economy in most cases. From an international view, most people in Europe and the United States work for economic reasons (Sakai, 2014). In contrast, the Japanese have unique work values that do not give importance to economic reasons, and they characteristically work to acquire skill, because the work is worthwhile, for social reasons, and so on (Sakai, 2014; Engel, 1988; Wolf, 2013). Recently, however, Japanese work style has varied with the change of the industrial structure due to the loss of the Japanese style of management and the introduction of Western-style performance-based salary systems (Tae-sook, 2013). For this reason, the manner of career formation is significantly changing in Japan. Difficulty especially arises in the acquisition of professional knowledge or skills because employment status is not stable in occupations for which they are required (Hiromori, 2012; Fujimoto, 2008). Why do young people pursue what they want to do, rather than economic stability, in this situation? This study focused on the consciousness and expertise of young people who chose high-specialty occupation. This study focused on traditional craftspeople because their occupation was considered to require high specialty; however, it did not have economic stability due to the industrial decline in the first half of the 1990s. The formation process of professional identity in young craftspeople will be discussed from a psychological viewpoint.

\subsection{Definition of Professional Identity and About Maki-e Craftspeople}

Vocational identity, which is a subjective sensation experienced through the interaction between the rules of an occupational group and a value system, is one of the important developmental tasks of adolescence (Erikson, 1968), while professional identity is the vocational identity of a professional person who has certain qualifications (Tatara et al., 1984). However, professional identity has not been clearly distinguished from vocational identity in previous research. Okamoto's research about professional identity in potters, based on Ericson's theory, was considered to be a precedent of the research in this study (Okamoto, 2010, 2011); however, her participant did not have public qualification as a traditional craftsman because he did not belong to that production area based on the "Law for the Promotion of Traditional Craft Industries". As a fundamental problem, public qualification as a traditional craftsman is not necessary to work as one. Adding to this problem is the fact that the above professional identity is not applied to traditional craftspeople despite their professional knowledge and skill. Therefore, it has been determined that it does not matter whether the occupation requires qualification in this study. "Professional identity" in this study is defined as "a subjective sensation experienced through the interaction between the rules of an occupation, which requires professional knowledge and skill, and a value system".

This study focuses on Maki-e craftspeople. Maki-e was a traditional decorative technique of lacquer craft that was developed originally in Japan. Recently, the need for Maki-e has been declining due to the falling demand and the appearance of alternative technique, such as silk screen technique, while it is a representative craft. About a hundred craftspeople have above public qualification; however more than a hundred people take part in Maki-e work because there are many other craftspeople who do not have public qualification. The kinds of Maki-e are different from the dependence on the production area. This study thus focuses on Maki-e craftspeople with a traditional background in Kyoto, where a various techniques of Maki-e is demanded. There are only four Maki-e traditional craftspeople in Kyoto. To discuss about the professional identity of Maki-e craftspeople who have been handed over as Japanese unique craft for a long time gives an indication of considering the existence of other high-specialty occupation.

\subsection{Problem Identification and Aim of This Study}

Skill is one of greatest indexes that show the specialty of an expert. There are many studies about skill, as shown in the five-stage model of skill acquisition (Dreyfus \& Dreyfus, 1980). Skill has a great influence on the formation process of professional identity; however, it is more important to focus on the subjective sensation of how a person acquires skill than to evaluate skill level. Most previous research focused on skill acquisition, while the discussion of the consciousness of craftspeople was insufficient. There are many studies that analyze the skill of craftspeople using a scientific viewpoint and methods (Osman \& Zin, 2010; Hochin \& Nomiya, 2013); however, the skill is impossible to extract by quantification because skill it is based on tacit knowledge (Polanyi, 1966). 
Additionally, use of a visualized training technique does not always generate an expert; as shown in previous research, an expert's performance decreases when judging him based on his knowledge (Dreyfus \& Dreyfus, 1979). Therefore, the consciousness of craftspeople about various expertise processes excluding skill is also important when considering the formation process of professional identity.

Skilled craftspeople are important as role models in the discussion of the formation process of professional identity for young craftspeople. Skilled craftspeople have high levels of skill and long careers in the industry. The environments of skilled craftspeople and young craftspeople are not same because the environment of the traditional crafts industry has been changing year by year; however, it is possible to extract not only the formation process of professional identity for young craftspeople but also both the changeable and unchangeable aspects of the professional identity by comparing them.

This study then focused on the formation process of the professional identity of Maki-e craftspeople, which was one of the Japanese traditional crafts. This study aimed to clarify the professional identity of Maki-e craftspeople by comparing skilled craftspeople and young craftspeople. It is important to achieve this aim as it will achieve greater understanding of career formation in highly specialized occupations.

\section{Experiment}

\subsection{Participants}

The participants were four Maki-e craftspeople who belong to the Kyoto-hu Butsugu Cooperative. The four craftspeople held different positions because it is reported that difference in position has an influence on consciousness (Machida et al., 1997). All participants had training experience in the same studio. Participant information is shown in Table 1.

\subsection{Methods}

Details of the research were explained to the participants in advance, and the interviews were conducted upon their consent. The contents of the interviews were recorded with an IC recorder, also upon their consent. Semistructured interviews were conducted with the following questions.

a1) What was your motive for starting a career as a Maki-e craftsperson?

a2) What is your coping method for occupational troubles?

a3) How did you learn to be a Maki-e craftsperson?

a4) When did you feel that you were suitable or unsuitable for this work?

a5) What things are necessary for this work?

a6) What is the value of the work you do in this occupation?

a7) Why do you continue this work?

a8) Who, or what, influences the value of your work?

\subsection{Analysis}

All recorded data was transcribed, and only portions were analyzed upon the participants' consent. Important words that would have an influence on the formation of professional identity were extracted and compared among the four participants. Discussions were held with some researchers to ensure that they were not biased.

\begin{tabular}{|c|c|c|c|c|c|}
\hline Participant & Age & Length of service & Gender & Start of career & Position \\
\hline A & 60 & 42 & Male & After graduating from University & $\begin{array}{c}\text { Manager of A's studio } \\
\text { Traditional craftsperson } \\
\text { Craft artist University professor }\end{array}$ \\
\hline $\mathrm{B}$ & 67 & 52 & Male & After graduating from junior high school & $\begin{array}{l}\text { Employee of A's studio } \\
\text { Banto (Head clerk) } \\
\text { Traditional craftsperson }\end{array}$ \\
\hline $\mathrm{C}$ & 33 & 14 & Female & After graduating from special school & $\begin{array}{l}\text { Independent of A's studio } \\
\text { Traditional craftsperson }\end{array}$ \\
\hline $\mathrm{D}$ & 32 & 8 & Female & After graduating from special school & Employee of A's studio \\
\hline
\end{tabular}




\section{Results}

a1) What was your motive for starting a career as a Maki-e craftsperson?

Only participant A, whose family business was Maki-e, had been concerned with Maki-e since childhood. Participant A said, "It was natural for me to take over my family business, and I did not hesitate to do it". Participant B started Maki-e work through a human connection, and he said, "I was not interested in Maki-e or drawing pictures essentially". Participants C and D loved to create things; however, neither participant was particular about Maki-e. They had both majored in Maki-e at a special school, and that experience led them to start their career as Maki-e craftspeople. Only participant $\mathrm{C}$ wanted to be a craftsperson; however, she reflected on her past and said, "The definition of craftspeople was obscure and I was not able to image it clearly". The hometown of participant $\mathrm{D}$ is a production area for lacquer crafts; however, it was not directly related to her choice to be a Maki-e craftsperson. The reasons participant $\mathrm{C}$ and $\mathrm{D}$ gave for choosing participant A's studio were "the working condition" and "I can try various work here, and it will be helpful for continuing Maki-e work in the future", respectively. Then, it was shown that participants A and B did not choose to be Maki-e craftspeople voluntarily, while participants C and D did. None of the participants strongly desired to be Maki-e craftspeople before deciding to pursue the occupation, and none of them chose this career based on having confidence in and talent for Maki-e.

a2) What is your coping method for occupational troubles?

All participants had trouble with the social aspects of their work. Both skilled craftspeople detected a difference in the working conditions of their friends, who had other occupations, such as white-color jobs, and because their salaries as craftspeople were not as high as that of other occupations. However, their coping methods in the face of this trouble and their thoughts about continuing to work were very different. As a coping method, participant A was apprenticed to two craft artists, and after that he said, "I did not hesitate to continue my work because I desired to succeed at my job, the same as my masters". Participant A reselected the occupation of Maki-e craftsperson voluntarily through this experience. On the other hand, participant B felt that he had no choice but to work as a Maki-e craftsperson. He continued working with encouragement from the surrounding people when he wanted to quit; he did not do this voluntarily.

Both young craftspeople had trouble, not with the working conditions, but with the current contents and condition of Maki-e. Both participants $\mathrm{C}$ and $\mathrm{D}$ felt that it was important not only to produce Maki-e but also to get work and transmit information after they started to work at the studio. This was because participant A always tried hard to get work and make announcements to the public. The coping methods of participants $\mathrm{C}$ and $\mathrm{B}$ were not the same because they held different positions; however, both thought of their coping methods voluntarily. Participant $\mathrm{C}$ was trying challenging, new things after her independence. She said, "Now, I am learning about some alternative natural materials that are used for Maki-e because I did not have enough knowledge about them", and she was developing a new personal relationship. Participant D worried about the current drop in sales of Maki-e work, and she said, "We have to find a new demand or a different demand than we have had before to continue this work".

Hence, participants A, C, and D chose their occupations as Maki-e craftspeople voluntarily, including the reselection of career by participant A after he worked for some years. They each coped with their troubles voluntarily, while participant B, who chose his occupation passively, did not cope with his trouble.

a3) How did you learn to be a Maki-e craftsperson?

When participants A and B were young, they were pressed for time producing a lot of work because there was great demand for Maki-e in those days. They realized that their skill was based on that experience. Specifically, participant A said, "I had acquired my skill by having done a lot of work", and "I had trained and raised my skill so I would be second to none, and I spent much time infuriatingly acquiring skill". Participant B said, "When I was young, I had been pressed for time because we had a lot to do", and "I had spent a very long time working because I thought that I should work more than others and learn, even if just a little earlier". However, their form of work was not same. Participant A did all of the processes of the work alone as a craft artist, while participant B said, "I had never done all of the processes of the work because it was efficiency-oriented".

Participant $\mathrm{C}$ also indicated that she had been taught efficiency-oriented work during her training days, though the age at which she was trained differed from that of participants A and B. Participant D did not make a similar remark; however, all of the participants pointed out that they had learned the skill by doing a lot of work and through assiduous effort. From the remarks of participants B, C, and D, the orientation procedure in the stu- 
dio indicated that it was necessary to ask the manager or the senior person if there was anything they did not know how to do. Additionally, all of the participants referred to the experience of learning from their mistakes.

As mentioned above, three common ways, which are unrelated to when they were trained, to learn Maki-e in the studio were indicated. The first was through doing a lot of work and assiduous effort, the second was asking, and the third was learning from mistakes. Remarks were different between participant $\mathrm{D}$, who has had the shortest career, and the other three participants. The other three participants emphasized the efficiency of their work.

As another manner of learning Maki-e, participant A pointed out experience as a craft artist and the circumstances of it being the family business. Participant B said, "Learning by watching the others who are skilled is just like glancing at the finished work when I package it before shipping". This remark means that he had learned from objects such as finished work. Participant $\mathrm{C}$ learned from comparing her work and that of others. She said, "I thought about what the difference was between skilled craftspeople and me" Participant D explained her basic attitude, saying, "If I do not understand, I ask"; however, she also said, "I came to ask skilled craftspeople more because my junior disciples positively ask skilled craftspeople about things when they have a question". Therefore, it is indicated that the subject that is learned depends on each participant.

a4) When did you feel that you were suitable or unsuitable for this work?

Participants A, C, and D felt that they are suitable for Maki-e when their targets were achieved or work went well. Participant A, unlike the other participants, felt that he was suitable for Maki-e when he acquired the skill not as the family business but as a craft artist. He said, "I felt a sense of accomplishment when I was able to create the work or expression that I had aimed for", and, "I felt that I could win the prize certainly after I had felt it". He recognized the reason for this, saying, "Because my skill and expressiveness had exceeded a constant level, certainly". Participant C said, "I had the experience that one day I was suddenly able to do well; however, I do not know the reason", and, "I had become able to do some work my own way five years after I had started my career in this studio". In addition, participant C said, "Though there is work that I cannot do yet, the work I became able to do is due to patience". Participant D said, "I feel I am suitable for Maki-e when I can do the work well, though I mistook it in the past". Participant D also said, "I feel that my ability to see and comprehend Maki-e is increasing to greater than before", and, "My sensitivity has been overwritten year by year", On the other hand, only participant B felt that he was suitable for Maki-e when he was prized by the master or when he was assigned work. He said, "I felt that I was able to do work well when I was assigned work", and, "My skill was improved and the speed of work became quick when I felt I could do it well".

a5) What things are necessary for this work?

All participants had the common opinion that a special talent for Maki-e work is unnecessary, and they also thought that repetitious work and effort were important elements if one were to work as a Maki-e craftsperson. Participant A said, "Technique is made up for in effort, though it is best to be deft", and, "Two years is enough time to acquire the technique for each process". Participant C said, "Repetition makes you become good at the work if you are not initially good at it". Participants B and D thought artistic ability to be unnecessary if you existing designs were used. Participant D especially thought that repetition, experience, and effort were important if the work is based on existing designs. She said, "Maybe five years is enough time to acquire the technique". However, participant A said, "Ten years is not enough time to learn to do various thing", and participants B and $\mathrm{D}$ also pointed out that artistic ability, like artistic taste or design ability, is needed to create something new. Participant D said, "Sense is yet another problem, though technique is made up for in effort".

Participants A, C, and D shared a common approach in that they think of their work socially. Participant A said, "It is important to acquire skill and technique; however, it is also important to understand the social aspects that Maki-e has". Participant C said, "Just motivation for work is enough if there are enough demands for Maki-e socially that you can get work". Participant D said, "It is more necessary to create a new demand than to address a skill-based or technical problem because the amount of work has decreased recently". In addition, opinions about important mental aspects were obtained, for example, positivity, curiosity, high motivation, obedience, cheerfulness, a love for creating things, and patience for repetitive work.

a6) What is the value of the work you do in this occupation?

All participants were aware of the crisis of decreasing demand for Maki-e, regardless of the quality of the craftsperson's skill. Participant A said, "It is important to change our work according to economic activities". Participant B said, Responding to demands from clients is more important than skill level", and he said, "Our Maki-e work can respond to various demand", indicating why their studio could continue in this situation. Participant C said, "Attracting customers positively is important because we do not have much work now". Partici- 
pant D pointed out that Maki-e has poor demand and low necessity in daily use, though she thought that Maki-e would not and should not disappear.

Though all of the participants shared a common opinion that the Maki-e technique is not special, participants $\mathrm{B}, \mathrm{C}$, and D felt that the work itself is. As special elements of the work of Maki-e, Participant B pointed out that the tools and materials do not change so much, participant $C$ pointed out that they could make their own work through Maki-e, and participant D did not know what to answer when asked for the name of her occupation. Participant A thought that Maki-e is not presently special work, saying, "Actually, I thought that Maki-e is special work; however, my precursors would feel the same as I do". Participant A thought that Maki-e built character because it entails a target and is like climbing a mountain within himself. Participant A compared the past and current situation of craftspeople, saying, "The work of craftspeople had been easy to live with because it was just repetition when I was young", and, "However, that repetitive form has changed". Participant B said, "Our Maki-e style is one of many Maki-e; however, we contribute by handing it over to future generations". However, participant B emphasized the efficiency and benefit of the studio when he considered the skill acquisition of junior disciples. Participant B also emphasized strongly, "We never must make trouble for our clients", and he thought that human relations and delivery dates are important. On the other hand, participant B said, "I had only responded to the demand of clients, so that I have never contrived any work on my own". Participant D said, "I am protected by my master and senior disciples because I am a disciple now, and it is different with a general company employee".

a7) Why do you continue this work?

Participants A, C, and D indicated that the reasons to continue Maki-e were interest and sense of accomplishment. Participant A was interested in Maki-e itself, and he felt interested and satisfied about upbringing the disciples. Participant A also said, "I have many things I want to do because I am not satisfied with my current skill level yet". Participant $C$ expressed that she felt a sense of accomplishment: "When I was able to create a work just as I planned and I was able to make it beautiful". Participant D said, "I love to make something original", and, "I think Maki-e is worthwhile work because the more I do it, the more I become well, and there are a lot of things I have to learn". On the other hand, participant B said, "I am continuing Maki-e regardless of whether I like or dislike it", and, "I have worked earnestly for a living". He also said, "I felt like I had been forced to work in my first five years; however, my work had gone well and I felt interest and joy because I had come to understand various things after that", and, "I feel Maki-e is worthwhile work because it leads to the future". In addition, participant B pointed out that he is continuing Maki-e because he has an obligation to his masters and that his mind had been changed by his marriage.

Both participants $\mathrm{C}$ and D thought about how they will continue Maki-e in the future; however, their opinions were not same. Participant C said, "When I was in the studio, I had $70 \%$ toughness and $30 \%$ determination to become skilled", and, "After becoming independent, I felt that my work was a bit more worthwhile because my role was increasing". Participant $C$ felt happy that she could continue handwork as her occupation; however, she also felt that the responsibility, acquiring jobs, and responding to her clients after gaining her independence was difficult. Moreover, participant C said, "It is tough for me to think I must continue this work," and, "I want to meet expectations and support the people around me". On the other hand, participant D did not think as participant $\mathrm{C}$ did, saying, "I do not have any lack of confidence or any uneasiness because I think I will come to be able to do anything that I cannot yet do". Participant D also expressed positive thinking when she said, "I want to do something new in the future, whether I am here or not".

a8) Who, or what, influences the value of your work?

All participants were influenced by the people around them, such as the masters and senior disciples; however, only participant A was influenced by the social evaluation of his or his studio's work. Participant A expressed his own originality because he said, "I had been influenced by a lot of people and things; however, I am different from them, and I am just me". He also said, "I had realized that my and our work had been appreciated enough socially when I had been able to meet socially prominent people through the work". Participant B said, "It was good that I had worked with a gentle first master and a strict second master"; however, he also said, "I was different from participant A and other disciples because I had not chosen this work by myself". Only participant B compared himself to the others.

Participant $\mathrm{C}$ indicated that she was influenced by participants $\mathrm{A}$ and $\mathrm{B}$ and the former teacher at the special school; however, the influence of each person was different. Participant C said, "I had gotten a rough image of Maki-e through the experience that I had been impressed to see the work by a craft artist when I was a student at 
the special school". Participant D learned about various aspects, for example, technique and customer service, from the master and the senior disciples, and she also learned about having a learning attitude from the junior disciples.

\section{Discussion}

As indicated in the above results, the participants in this study were classified into two types. One is the spontaneous type, who chose to become Maki-e craftspeople and acted voluntarily, like participants A, C, and D; the other is the unspontaneous type, like participant B. These two types are discussed in this section.

\subsection{Learning, Necessary Things, and Work Value}

In regards to the common ways in which one learns at the studio, three ways- - through repetitious work and assiduous effort, asking questions, and learning from mistakes - were indicated. Participant B, the unspontaneous type, showed that he had been passive, had been forced to work, and had been pressed for time. On the other hand, participant A, a spontaneous type who had learned in the same situation as participant B, gained confidence in his skill by spending a great deal of time and effort. Participants $\mathrm{C}$ and $\mathrm{D}$, also the spontaneous type, also learned positively, for example, by comparing their attitudes and education to that of to others. The two types do not differ greatly in learning, but they do differ in how they think about learning.

The point to consider here is that this difference in thoughts about learning does not influence the ability to be a professional, as exhibited by participant $\mathrm{B}$, who has over fifty years of experience. As shown by the recent decrease in the industry, the amount of available Maki-e work is decreasing, which is why three participants (excluding participant $\mathrm{D}$, who has had the shortest career) emphasized the efficiency of their work. However, the basic learnings of Maki-e do not change, even when the surrounding environment does. Thus, the following two points would be more important than one's thoughts about learning to be a Maki-e craftsperson: repetitious labor and failure, and determination to achieve expertise.

The importance of repetition is also indicated as necessary to the continuation of working as a Maki-e craftsperson. All participants thought that experience based on repetition and effort was more important than talent. Participant C's experience of suddenly being able to do well one day is the result of repetition and effort, and the sensitivity of participant $\mathrm{D}$ has been overwritten over the years by the same. These results are thought to reveal the process of gaining expertise. The theory called the "10 year rule", which states that it takes more than 10,000 hours of deliberate practice to become an expert, had been advocated (Ericsson et al., 1993). However, the determinant of skill acquisition has not yet been revealed because it has been reported recently that the influence of the amount of deliberate practice on skill improvement depends on the domain (Macnamara et al., 2014). It was indicated that the experience of repetitious work has a great influence on the skill and technique acquisition of Maki-e craftspeople.

However, it is necessary to add that the importance of repetition does not mean that the work of craftspeople is the same as that done by a machine. As described above, the skill is impossible to extract by quantifying. This is because the skill of craftspeople is flexibly supported and not dependent on a condition (Shiose et al., 2004). Additionally, it is necessary that the skill of craftspeople not depend on pattern recognition via a manual but on individual contrivance and individuality (Shibata, 2006). Thus, the bodily knowledge of the Maki-e craftspeople is an ability that produces a certain result regularly if the condition is different, and this means that experience with repetitious work has a great influence on the acquisition of that ability. Additionally, the participants thought that acquisition of the Maki-e technique was not special; however, they used the words skill and technique separately. Therefore, it is though that they recognized the difference between skill and technique, and they think skill is a more specific concept than is technique.

In terms of work value, all participants thought that the work of Maki-e craftspeople possesses social specialty. The spontaneous type thought that social response was necessary, in particular due to the recent industrial trend. Thus, social ability would have a great influence on the formation of the professional identity of Maki-e craftspeople. Change in the work form of craftspeople would change significantly the condition of Maki-e in social industries according to participant A. Decrease in work demand directly leads to a decrease in opportunities to acquire skill because of the value of work repetition. That is to say, the surrounding environment of work between skilled craftspeople and young craftspeople is changing greatly, while the manner of learning Maki-e is changeless. Thus, not only skill is needed but also social response, as expressed by the spontaneous types, to 
develop one's professional career as a craftsperson. The fact that Maki-e is a traditional crafts product is not related to demand for it, despite its manufacture supporting the national culture. It is important to inform customers of the value of the traditional crafts products (Ryoke et al., 2008; Huynh et al., 2010). Hence, it is believed that an approach that takes social response into consideration from the view of both culture and industry is needed to support the continuation of Maki-e craftspeople in the future.

\subsection{Feeling Suitable, Desire to Continue Work, and Influential Person or Thing}

There were great differences between the spontaneous and unspontaneous types regarding feeling suitable to do their work. The spontaneous type felt suitable when their needs were satisfied, and the unspontaneous type felt this way when he was recognized by others. Human needs have five levels of need: physiological, safety, socialization, esteem, and self-actualization. Esteem has a lower subcategory that includes the need for respect from others, including a need for status, recognition, fame, prestige, and attention, and a higher subcategory that includes self-esteem, skill or ability acquisition, self-confidence, and autonomy (Maslow, 1943). The lower levels of esteem needs for the unspontaneous type were satisfied with recognition from others, and the higher level of esteem needs were satisfied after that. It is believed that recognition from others played an important role for the unspontaneous type because this type had not aimed to create Maki-e originally. On the other hand, the spontaneous type satisfied their higher level of esteem needs without others. The spontaneous type chose to become Maki-e craftspeople on their own, and they felt pleasure and had interest in making something. An instance wherein submersion in the creative process and high satisfaction were achieved through work, which are important occupational elements, was also reported (Scheerer et al., 2004). Maki-e work leads to self-realization directly in the case of the spontaneous type. Thus, spontaneity in choosing an occupation has an influence on the differences between types.

Spontaneity in choosing an occupation is also related to feeling suitable and the desire to continue one's work. As the reason to continue working, the spontaneous type indicated their interest and a sense of accomplishment when making something, and they worked based on internal factors and self-motivation. On the other hand, the unspontaneous type continued working due to external factors, for example, the obligation to his masters and the need to make a living. The unspontaneous type also thought that responding to clients was important, so that this type had never cogitated making Maki-e voluntarily. Furthermore, the unspontaneous type realized that his opportunity to find work had an influence on his desire. Thus, the difference in reasons to choose this line of work is thought to have an influence on both the reasons why Maki-e craftspeople think they are suitable for their work and their desire to continue it. The manners of self-realization based on the difference in reasons to choose this type of work are shown in Figure 1.

In terms of influential people or things, all participants were influenced by the surrounding people who work or once worked as Maki-e craftspeople because it is difficult to learn their trade from people who work in other fields. All spontaneous types determined their goals and made decisions based on various interactions, despite the difference in their positions. Participant A recognized his originality while he was influenced by the surroundings people, and only participant A obtained a sense of fulfilment from his work by obtaining social eval-

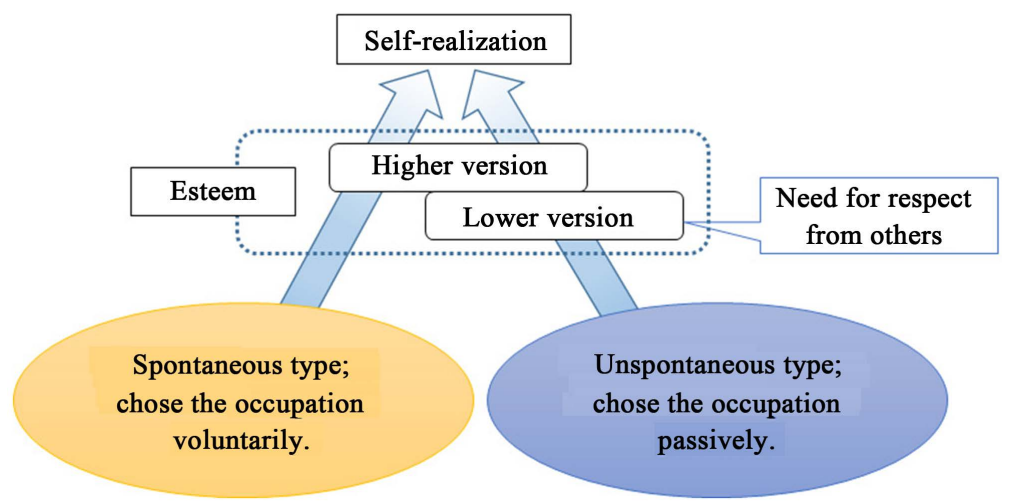

Figure 1. The manner of self-realization based on the difference in consciousness when choosing an occupation. 
uation. Participant A was conscious of social response in particular because he saw things from the viewpoint of a manager, as shown in the previous research (Machida et al., 1997). However, participant A desired to not only obtain social evaluation but also create Maki-e and train disciples. Therefore, it is believed that, for participant A, the creation of Maki-e and the upbringing of disciples have great influence on achieving goals and the desire to continue working. Participant B, an unspontaneous type, also thought it important to hand over Maki-e to the next generation; however, there were great differences among the skilled craftspeople about the thought of taking over because participant $\mathrm{B}$ emphasized the efficiency and benefit of his work.

In common with participant $\mathrm{B}$, participant C's spontaneous type, strongly emphasized the existence of clients; however, their reasons were different. Participant $\mathrm{C}$ had trouble reconciling the difference between what she wanted to do and what she should really do and she felt the necessity of gaining social response after becoming independent. In short, the influence of the existence of clients on participant $\mathrm{C}$ depends on her contradiction. Participant B, on the other hand, thought that clients played the leading role. This difference is thought to depend on whether the craftsperson feels like he or she belongs to the studio. It is thought that participant C's thought process is getting closer to that of participant A's from the viewpoint of a manager. In addition, Participant $\mathrm{D}$ concentrated on improving her skill, and she had a positive attitude about continuing to work while thinking about social response. Participant D did not have uneasiness similar to participant C's. This difference depends on the responsibility associated with their positions because participant $C$ has to find jobs herself while participant $\mathrm{D}$ is given jobs through the studio.

\subsection{Comprehensive Discussion}

As described in Section 1.1, the Japanese have unique work values that do not give importance to economic reasons for pursuing careers. However, the results of this study show that there are two types of Maki-e craftspeople. One is the spontaneous type whose work value is based on skill acquisition and the belief that making Maki-e is a worthwhile endeavor; the other is the unspontaneous type whose work value is based on economic reasons and obligation. Participant B is the notable instance of the latter type in this study. Doing Maki-e and making something are methods of self-realization for the spontaneous type, while participant B is a successful instance of someone who continued working as a Maki-e craftsperson without a special intention to create Maki-e. Does participant B's situation indicate that the intention to continue working as professional is unimportant?

For example, the experience of repetitious work has an important role in the identity of professional nursing, as it does that of Maki-e craftspeople (MacIntosh, 2003). However, nursing is an occupation with very high turnover rates globally (Hayes et al., 2012). In the case of nurses, higher work satisfaction and the greater group cohesion are important to one's choice to continue a nursing career (Shader et al., 2001). On the other hand, it was reported that there was a process through which nurses reconstructed their desire to continue nursing by finding occupational strengths through recognizing the difference between their ideals and the reality of their work and through thinking of it is just a job (Oe et al., 2014). Therefore, a clear-cut conclusion to one's work may be more important for an occupational professional than the working environment or intention, as shown with participant B.

A problem lies in whether or not participant B's result still applies to the occupation under an unstable economy. The demand for the work of craftspeople has been decreasing, and there is an unstable economy. It is thought that a strong desire to continue working is required if people are to do so in an unstable economy. Skill alone does not always make a steady living, and a lot of patience and effort are needed to acquire skill. It is thought that a spontaneous choice of career has great meaning when continuing to work, after understanding this contradiction. In the 1960s, when participant B started work, skill acquisition was not separate from making a stable living. Therefore, participant B may have chosen this work for unspontaneous reasons; therefore, current young craftspeople do not always build a long career if they make the same choices as participant B.

It is difficult to work for economic reasons when considering the present situation of professional occupations, like craftspeople. Basically, people should choose an occupation with high economic benefits if they are motivated by economic reasons. With this in mind, it is valid to think that people engaged in work that is difficult to gain economically from must value the work and necessary skills. Thus, it is natural that the professional identity of someone under an unstable economy excludes economic factors. Based on the above discussion, the formation process of the professional identity of Maki-e craftspeople is shown in Figure 2. 


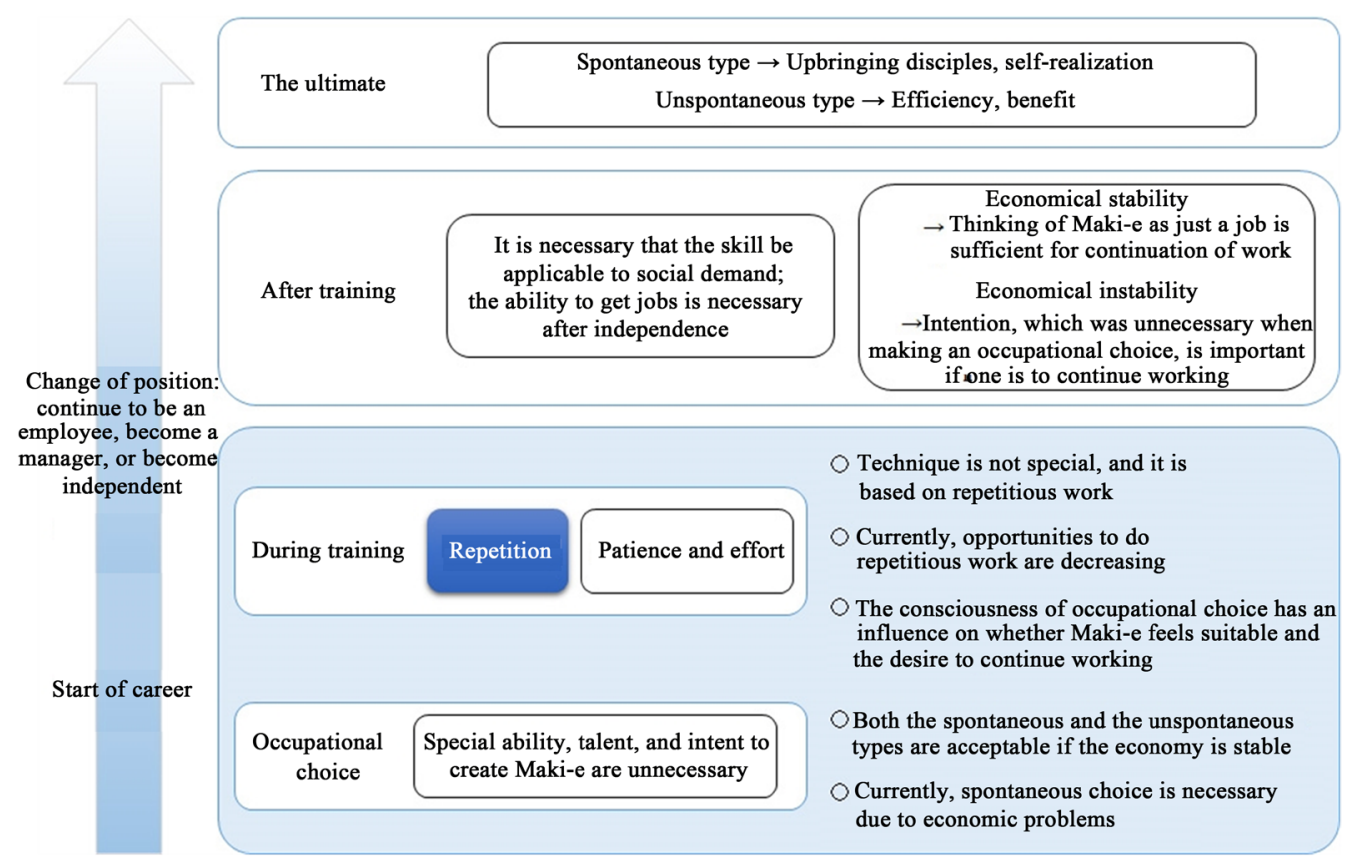

Figure 2. The formation process of the professional identity of Maki-e craftspeople.

Another point to consider is that the tradition of Maki-e as part of the national culture is supported by the existence of the above professionals. Traditional crafts would need to change their style, which has been passed down for so many years, if everyone considered only their economic value. The skill development of the traditional crafts has been supported by the apprentice system, basically; however, that system was altered by a social change after the Meiji period (Sato et al., 1962). Furthermore, the apprentice was precluded by the Japanese Labor Standards Law enacted in 1947. Because of these changes, it became realistically difficult to retain the apprentice system. The Japanese social system has been changing the existence of craftspeople. The conversion from handwork to mechanization is advancing constantly. This is just the current trend, and it is difficult to establish an industry by regressing. Both traditional crafts and those employed making them need to respond to the change of contemporary society. It is shown that the professional identity of Maki-e craftspeople, who have the two aspects of "culture and industry," changed along with society. Accordingly, the unchangeable skill acquirement method shown in this research may change in the future. In any case, we have to consider that it is necessary to develop a foundation for supporting traditional crafts and craftspeople as aspects of national culture and industry, including both the economic problems faced by the industry and the meaning of the work.

\section{Conclusion}

The following unchangeable aspects of the professional identity of Maki-e craftspeople were shown through this research.

A special ability, talent, and intention to create Maki-e are unnecessary when choosing Maki-e craftsperson as an occupation.

Maki-e craftspeople do not think that the Maki-e techniques are special; however, they think that skill is different regarding technique and that their occupation has social specialty.

The technique of Maki-e can be acquired through repetition of work; however, other elements, for example, a sense for the craft and an artistic talent, are needed to create something unique or to do various things excluding the work of craftspeople.

Furthermore, the professional identity of Maki-e craftspeople over the course of the social changes was shown in the difference between skilled craftspeople and young craftspeople.

The formation process of professional identity depends on the reasons for occupational choice because feeling suitable for the work and desire to continue working are different from those reasons. 
A spontaneous choice and strong intention to become a Maki-e craftsperson are needed in the current economic situation, while a special intention to pursue Maki-e was unnecessary in the past when a person was able to think of the career as just a source of income.

\section{Acknowledgements}

The study was financially supported by the Sasakawa Scientific Research Grant from The Japan Science Society (Grant Number 27-137).

\section{References}

Baker, J., Lovell, K., \& Harris, N. (2006). How Expert Are the Experts? An Exploration of the Concept of "Expert" within Delphi Panel Techniques. Nurse Researcher, 14, 59-70. http://dx.doi.org/10.7748/nr2006.10.14.1.59.c6010

Dreyfus, S. E., \& Dreyfus, H. L. (1979). The Scope, Limits, and Training Implications of Three Models of Aircraft Pilot Emergency Response Behavior. California University Berkeley Operations Research Center, ORC-79-2.

Dreyfus, S. E., \& Dreyfus, H. L. (1980). A Five-Stage Model of the Mental Activities Involved in Directed Skill Acquisition. California University Berkeley Operations Research Center, ORC-80-2.

Engel, J. W. (1988). Work Values of American and Japanese Men. Journal of Social Behavior \& Personality, 3, $191-200$.

Ericsson, K. A., Krampe, R. T., \& Tesch-Romer, C. (1993). The Role of Deliberate Practice in the Acquisition of Expert Performance. Psychological Review, 100, 363-406. http://dx.doi.org/10.1037/0033-295X.100.3.363

Erikson, E. H. (1968). Identity: Youth and Crisis. New York: Norton.

Fujimoto. M. (2008). Anomie of the Impact by an Institutional Change on Professionals. Japanese Sociological Review, 59, 532-550. http://dx.doi.org/10.4057/jsr.59.532

Hayes, L. J., O’Brien-Pallas, L., Duffield, C., Shamian, J., Buchan, J., Frances, H., Heather, K. S. L., \& North, N. (2012). Nurse Turnover: A Literature Review-An Update. International Journal of Nursing Studies, 49, 887-905. http://dx.doi.org/10.1016/j.ijnurstu.2011.10.001

Hiromori, N. (2012). Career and Skill Development of Women in "Professional Occupations"-An Interview of a Librarian and Dietician. Journal of Aomori University of Health and Welfare, 13, 1-11.

Hochin, T., \& Nomiya, H. (2013). Analysis of Pauses Toward Transmitting Traditional Skills. Proceedings of the 2013 14th ACIS International Conference on Software Engineering, Artificial Intelligence, Networking and Parallel/Distributed Computing (SNPD), Honolulu, 1-3 July 2013, 414-419.

Huynh, V. N., Yan, H., \& Nakamori, Y. (2010). A Target-Based Decision-Making Approach to Consumer-Oriented Evaluation Model for Japanese Traditional Crafts. IEEE Transactions on Engineering Management, 57, 575-588. http://dx.doi.org/10.1109/TEM.2009.2025494

Machida, T., Kobayashi, M., \& Miya, N. (1997). Occupational Consciousness of Craftsmen in Japanese Traditional Craft Industry. Japanese Society for the Science of Design, 44, 13.

MacIntosh, J. (2003). Reworking Professional Nursing Identity. Western Journal of Nursing Research, 25, 725-741. http://dx.doi.org/10.1177/0193945903252419

Macnamara, B. N., Hambrick, D. Z., \& Oswald, F. L. (2014). Deliberate Practice and Performance in Music, Games, Sports, Education, and Professions a Meta-Analysis. Psychological Science, 25, 1608-1618. http://dx.doi.org/10.1177/0956797614535810

Maslow, A. H. (1943). A Theory of Human Motivation. Psychological Review, 50, 370-396.

Oe, M., Tsukahara, S., Nagayama, Y., \& Nishimura, C. (2014). Acquisition Process of the Motivation to Remain in Nursing among New Graduate Nurses. Japan Academy of Nursing Science, 34, 217-225. http://dx.doi.org/10.5630/jans.34.217

Okamoto, Y. (2010). Generativity of Professional Identity in Potters I: An Analysis and Some Considerations on Prof. Tsunehide Shimabukuro's Life and Professional Works. Hiroshima Psychological Research, 10, 121-145.

Okamoto, Y. (2011). Generativity of Professional Identity in Potters II: A Microanalysis on Achievement and Successive Process of Potters' Identity through Master-Student Relationship at Tsunehide Shimabukuro Studio. Hiroshima Psychological Research, 11, 173-187.

Osman, S., \& Zin, N. A. H. M. (2010). Proposed Model for Courseware Development of Virtual Teaching and Learning Traditional Craft. Proceedings of the 2010 International Symposium in Information Technology (ITSim), Kuala Lumpur, 15-17 June 2010, 1-6. http://dx.doi.org/10.1109/ITSIM.2010.5561333

Polanyi, M. (1966). The Tacit Dimension. London: Routledge \& Kegan Paul. 
Ryoke, M., Nakamori, Y., \& Huynh, V. N. (2008). Personalized Recommendation for Traditional Crafts Using Fuzzy Correspondence Analysis with Kansei Data and OWA Operator. Interval/Probabilistic Uncertainty and Non-Classical Logics Advances in Soft Computing, 46, 311-325. http://dx.doi.org/10.1007/978-3-540-77664-2_24

Sakai, M. (2014). What Kind of Feature Does the Japanese Professional Career Have and What Kind of Change Does It Show. Journal of the Open University of Japan, 32, 25-43.

Sato, M., Sada, G., Haneda, A., \& Itagaki, M. (1962). Totei kyōiku no kenkyū: Sikki totei no shakaishi teki bunseki. Tokyo: Ochanomizushobo Co., Ltd. (In Japanese)

Scheerer, C. R., Cahill, L. G., Kirby, K., \& Lane, J. (2004). Cake Decorating as Occupation: Meaning and Motivation. Journal of Occupational Science, 11, 68-74. http://dx.doi.org/10.1080/14427591.2004.9686533

Shader, K., Broome, M. E., Broome, C. D., West, M. E., \& Nash, M. (2001). Factors Influencing Satisfaction and Anticipated Turnover for Nurses in an Academic Medical Center. Journal of Nursing Administration, 31, 210-216. http://dx.doi.org/10.1097/00005110-200104000-00010

Shanteau, J., Weiss, D. J., Thomas, R. P., \& Pounds, J. C. (2002). Performance-Based Assessment of Expertise How to Decide If Someone Is an Expert or Not. European Journal of Operational Research, 136, 253-263.

Shibata, S. (2006). Craftsmanship as Bodily Knowledge (Exploring the Japanese Image). Language and Culture Research Series, 5, 95-114.

Shiose, T., Kawakami, H., \& Katai, O. (2004). Knowledge Management for Proficient Skill-Transfer. IPSJ SIG Technical Report, 66, 9-16.

Tae-sook, M. (2013). Actual Situations of the Management by Performance in Japanese Firms and Its Issue. The Sanken Ronshu, $44 \cdot 45,15-25$.

Tatara, M., Miyashita, K., \& Okamoto, Y. (Eds.) (1984). Aidentiti kenkyū no tenbō I. Kyoto: Nakanishiya Co., Ltd. (In Japanese)

Van Gog, T., Paas, F., \& Van Merriënboer, J. (2005). Uncovering Expertise-Related Differences in Troubleshooting Performance: Combining Eye Movement and Concurrent Verbal Protocol Data. Applied Cognitive Psychology, 19, $205-221$.

Wolf, R. (2013). Management Relations in the Work Culture in Japan as Compared to That of the West. Innovative Journal of Business and Management, 2, 116-122. 